\title{
Shading and layout influence on flats energy performance of an apartment building
}

\author{
Iole $\mathrm{Nardi}^{1, *}$, and Marialisa Sarcina ${ }^{2}$ \\ ${ }^{1}$ ENEA, DUEE Department, 00123 via Anguillarese 301 Santa Maria di Galeria (Rome), Italy \\ ${ }^{2}$ Via S.Dorotea, 75C, Scoppito (AQ), Italy
}

\begin{abstract}
Giving the need for environment protection and energy need reduction, especially in the building sector, it is important to clearly understand what influences, and to what extent, buildings' energy performance. In this work, an apartment building has been considered, and the influence of shadings and of flats layout on the energy performance ratings are evaluated. The case study is a building of the '90s, which has been demolished and re-built (2016) according to the actual energy requirements. For each of the 16 flats of the building, the energy certificate has been retrieved in the two configurations: before and after reconstruction. From the analysis of the specific energy consumption, and of their components (i.e. energy need for ventilation, transmission losses, solar gains), in the two configurations, a comparison amongst the flats has been drawn. Results show that the apartment layout influences the solar gains, but this influence (in percentage) is higher in the "ex-ante" configuration than in the "ex-post". Similarly, the energy gains are more relevant in the "expost" configuration, in which some apartments, although having higher dispersing surface, result to be more efficient due to their favourable exposition.
\end{abstract}

\section{Introduction}

The growing attention to building energy consumption and related environmental impact has led to the increasing spread of knowledge concerning these two aspects.

This, of course, demonstrates the interest to these issues, as also proven by the two common approaches followed: the top-down and the bottom-up.

In fact, on one hand, laws, regulations, technical standards push the search and achievement of ever higher energy performances and ever lower energy losses, also with the introduction of the buildings' energy label [1-2]. On the other hand, the final users are even more aware of the energy, environmental and economy effects of efficient housing [3-6].

\footnotetext{
* Corresponding author: author@email.org
} 
This, as foreseeable, has become also a driving force for the building sector, from the construction management to the rental or sales services [7-10]. It is clear that, at equal prices, the final user tends to be more attracted by the better energy label. However, the energy label by itself can mislead the proper evaluation of a building or flat. In fact, this datum is meaningless when not paired with the total energy consumption of the building itself [11]. In this paper, such point is focused, demonstrating that, according to the Italian building energy evaluation methodology, a better energy label does not directly imply a higher energy efficiency.

To this aim, an apartment building has been considered. The structure, originally built in the ' $90 \mathrm{~s}$, has been severely damaged by the L'Aquila earthquake of 2009, and, therefore, it has been demolished and re-built in 2016, according the newest requirement at the time. The energy certificate of the 16 flats of the building has been evaluated, both before and after the reconstruction, according to the technical standards in law in 2016. This way has been chosen to highlight the differences of the energy consumption and the modification on the energy label and on the possible "ranking" of the flats. Finally, the differences have been studied in light of considerations on the solar gains and on the transmission losses of each apartment, also according to its exposure, thus evaluating the effect of the surrounding buildings and of the solar path.

\title{
2 The case study
}

The selected building stands in the near outskirt of L'Aquila city, in central Italy (Figure 1). The building belongs to a social housing project dated back to 1992: 15 identical apartment buildings were built in the slope of a hill. The earthquake occurred in 2009 affected the concrete beam structure; therefore, this building was demolished and rebuilt in 2016, in compliance with the requirement in force in that year. Data were therefore taken directly form project.

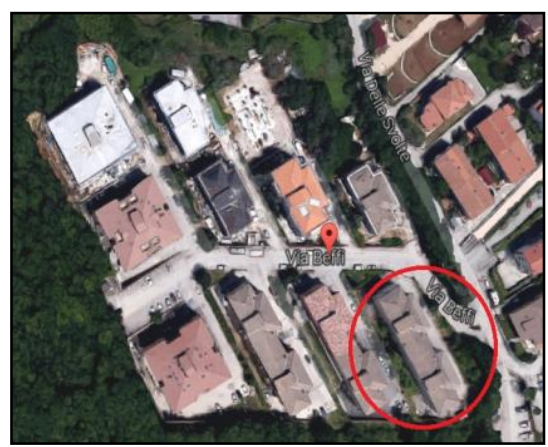

\author{
Country: Italy \\ Municipality: L'Aquila \\ Altitude: $721 \mathrm{~m}$ a.s.1 \\ Geographic coordinates: $42^{\circ} 21^{\prime} 14.43^{\prime \prime} \mathrm{N}$ - \\ $13^{\circ} 23^{\prime} 31.17^{\prime \prime} \mathrm{E}$
}

Degree Days: 2514

Fig. 1. Aerial view (from Google Maps) of the selected building and location details 
Table 1. Building technical features.

\begin{tabular}{|l|l|l|}
\hline & EX-ANTE & EX-POST \\
\hline External Wall & $\mathrm{U}=1,3 \mathrm{~W} / \mathrm{m}^{2} \mathrm{~K}$ & $\mathrm{U}=0,3 \mathrm{~W} / \mathrm{m}^{2} \mathrm{~K}$ \\
\hline Internal Wall & $\mathrm{U}=2,3 \mathrm{~W} / \mathrm{m}^{2} \mathrm{~K}$ & $\mathrm{U}=2,3 \mathrm{~W} / \mathrm{m}^{2} \mathrm{~K}$ \\
\hline Walls toward unheated staircase & $\mathrm{U}=1,5 \mathrm{~W} / \mathrm{m}^{2} \mathrm{~K}$ & $\mathrm{U}=0,9 \mathrm{~W} / \mathrm{m}^{2} \mathrm{~K}$ \\
\hline Slab & $\mathrm{U}=1,6 \mathrm{~W} / \mathrm{m}^{2} \mathrm{~K}$ & $\mathrm{U}=1,6 \mathrm{~W} / \mathrm{m}^{2} \mathrm{~K}$ \\
\hline Slab toward unheated spaces & $*$ & $\mathrm{U}=0,3 \mathrm{~W} / \mathrm{m}^{2} \mathrm{~K}$ \\
\hline Roof & $*$ & $\mathrm{U}=0,3 \mathrm{~W} / \mathrm{m}^{2} \mathrm{~K}$ \\
\hline Pillars & $\mathrm{U}=2,7 \mathrm{~W} / \mathrm{m}^{2} \mathrm{~K}$ & $\mathrm{U}=0,4 \mathrm{~W} / \mathrm{m}^{2} \mathrm{~K}$ \\
\hline Boiler & $\begin{array}{l}\text { Pmax }=30 \mathrm{~kW} \text { autonomus, } \\
\text { multi-stage, }\end{array}$ & $\mathrm{Pn}=107 \mathrm{~kW}$ centralized \\
\hline Solar thermal panels & Not installed & \\
\hline Photovoltaic panels & Not installed & $10 \mathrm{~kW}$ \\
\hline *Values derived from analogy with similar buildings \\
\hline
\end{tabular}

The structure conserved its main shape. However, some modifications took place:

- Balconies on the front side were enlarged, preserving their squared form, whilst small balconies were added on the rear side;

- The original autonomous heating system was replaced by a centralized one;

- The original fourth floor confined with an unheated attic; with the reconstruction, the fourth floor has a wooden roof directly towards the outdoor;

- The autonomous boilers, serving for the heating and hot water, were replaced by a centralized unit;

- An inertial storage tank (1500 litres) was added to the HVAC;

- Solar thermal panels were added and installed for water pre-heating;

- Photovoltaic panels were also added (total of $10 \mathrm{~kW}, 64 \mathrm{~m}^{2}$ of panels).

B1

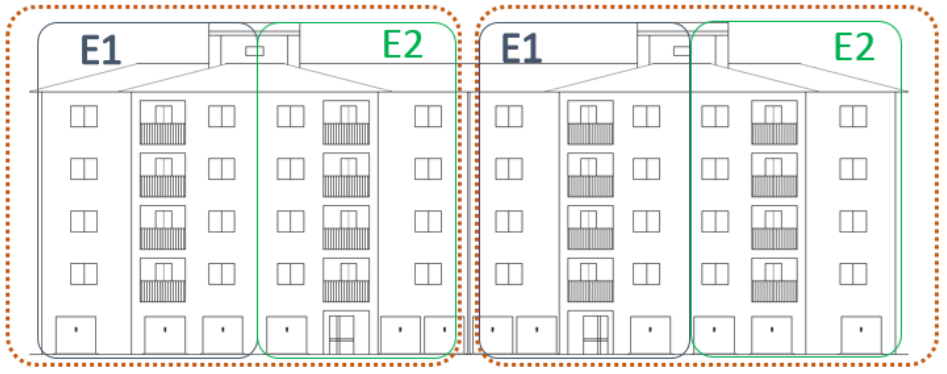

a) 


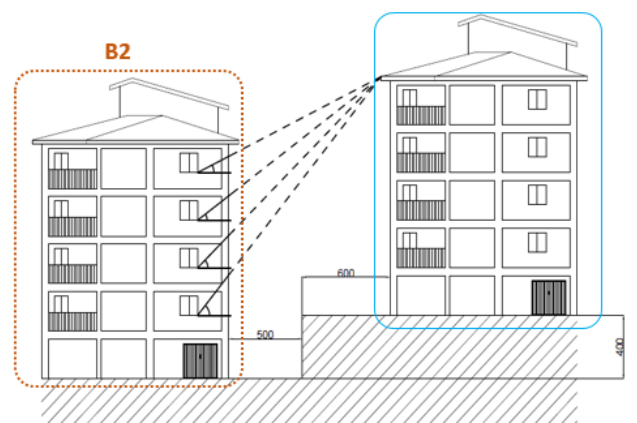

b)

Fig. 2. (a) Drawing of the selected building with conventional nomenclature, (b) side view with shadow projection and (c) solar path along the building

To ease the referral to the apartment, the following rule has been employed (Fig. 2a): since the centralized HVAC system serves two adjacent building, they've been both considered in the evaluations (B1 and B2). Each building has a staircase, that allows to access the flats on the left (E1) and on its right (E2). Each flat is then referred to its floor (from 1 to 4). Therefore, the writing B1.E2.3 refers to the apartment on the third floor of the right side of building B1. The considered buildings are shaded by other buildings standing in proximity (Fig. 2b), whose interference with the solar light is shown in (Fig. $2 \mathrm{c})$ and will be better analysed in the following sections.

\subsection{Evaluation method}

For the purposes of this work, it has been chosen to evaluate the energy performances of the flats as it would have been done for selling or renting, as required by Italian law. Hence, a commercial software was employed, to gather the energy labelling. Balconies, pillars, thermal bridges, shadings and all the information needed for a proper energy evaluation were modelled

By this method, several energy related indexes can be found, related to the energy services in the building. For residential buildings, they are: domestic hot water (w); heating (h); cooling (c). each one can be expressed as a sum of renewable (ren) or non-renewable (nren) contribution, according to specific conversion parameters. The sum of the energy performance indexes is the global energy performance (gl, tot) of the building that, in turn, can be expressed in terms of renewable and non-renewable contribution.

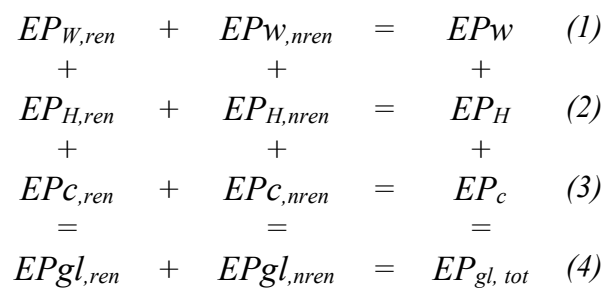

The energy certification expresses by a letter (label) the "ranking" of the global nonrenewable energy performance index, according to specific grades given by multiplying coefficients. Such ranking is expressed by letters (form better to worse: A4, 
A3,A2,A1,B,C,D,E,F,G). For this reason, results have been firstly expressed in terms of $\mathrm{EP}_{\mathrm{gl}, \text { nren }}\left(\mathrm{kWh} / \mathrm{m}^{2} \mathrm{y}\right)$, and secondly in terms of the solar heat gained $\mathrm{Q}_{\text {sol }}(\mathrm{kWh})$ and of the heat loss for transmission through the envelope $\mathrm{Q}_{\mathrm{tr}}(\mathrm{kWh})$ during the heating season (being this predominant given the degree days). All these results were gathered by using a commercial software in accordance to the Italian laws in force, in order to compare flats as it would be done by technicians and energy labellers.

\section{Results and discussion}

According to the Italian law in force, the energy label and $\mathrm{EP}_{\text {gl, nren }}$ have been calculated for each apartment, both for the "ex-ante" and "ex-post" case. Results are shown in Figure 3.

Before reconstruction, each flat was classified as $\mathrm{G}$ (the worste energy performance in the grad). Flats of B1.E2 and B2.E1 have lower global indexes than their narrows, and this also happens with all the flats of the second and third floor, showing the dependence on the boundary conditions given by the presence of occupied flats in the nearby. However, differences can be high, in fact. After reconstruction, half of the apartments were classified as A1, the remaining with B. EP ${ }_{\mathrm{gl}, \text { nren }}$ ranged between $49,5 \mathrm{kWh} / \mathrm{m}^{2} \mathrm{y}$ of flat B2.E1.3 and 71 $\mathrm{kWh} / \mathrm{m}^{2} \mathrm{y}$ of flat B2.E2.4. Once again, flats of the second and third floor have lower global non-renewable energy consumption, but it does not directly correspond to higher grades.

To compare the behaviour of each building staircase, histograms of figure 4 are shown, referring to the $\mathrm{EP}_{\mathrm{gl}, \text { tot }}$ (thus, including the renewable contribution).

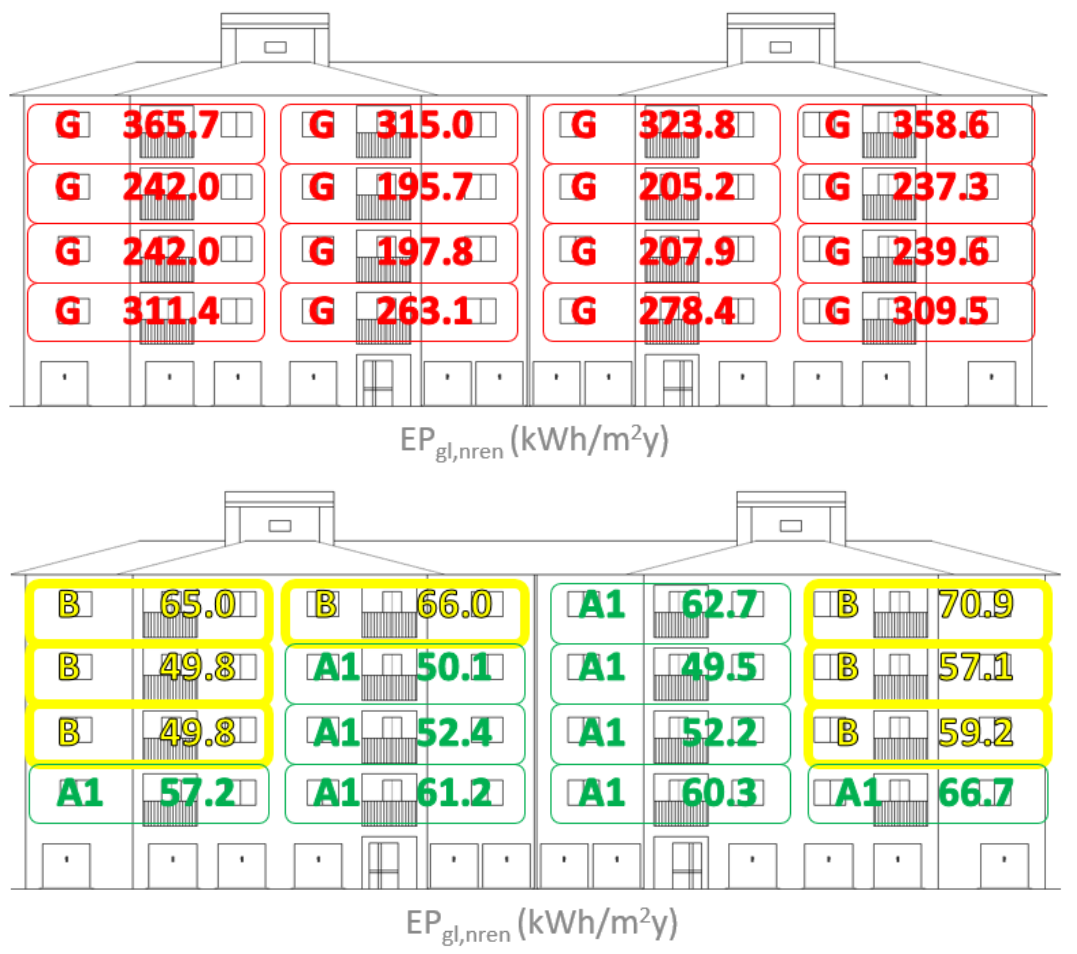

(a)

Fig. 3 Energy label and Global Non-renewable Energy Performance index of each flat: (a) Ex ante; (b)ex-post 


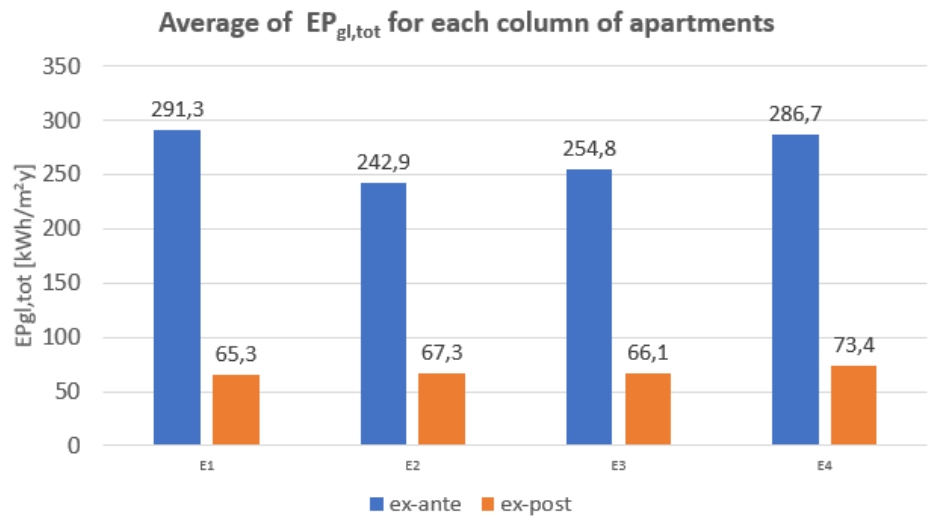

Fig. 4 Average, for each stair, of the global total energy performance index, before and after reconstruction.

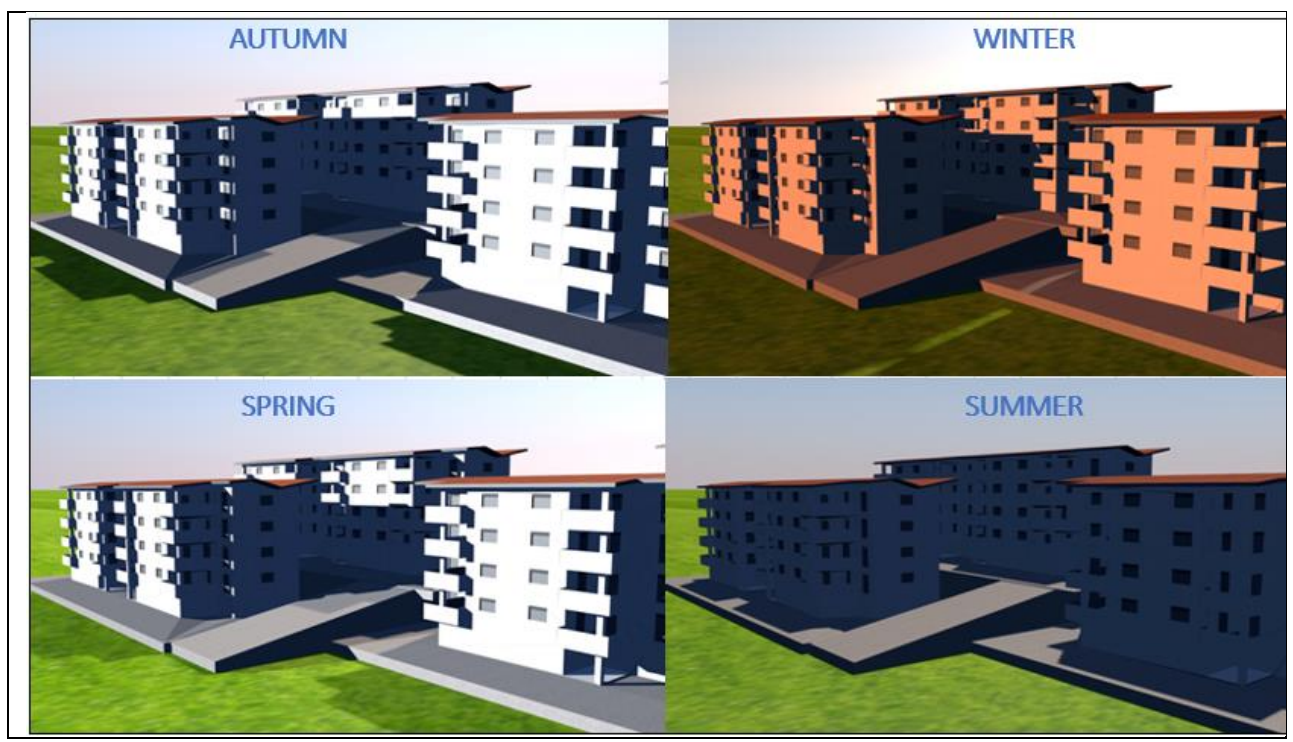




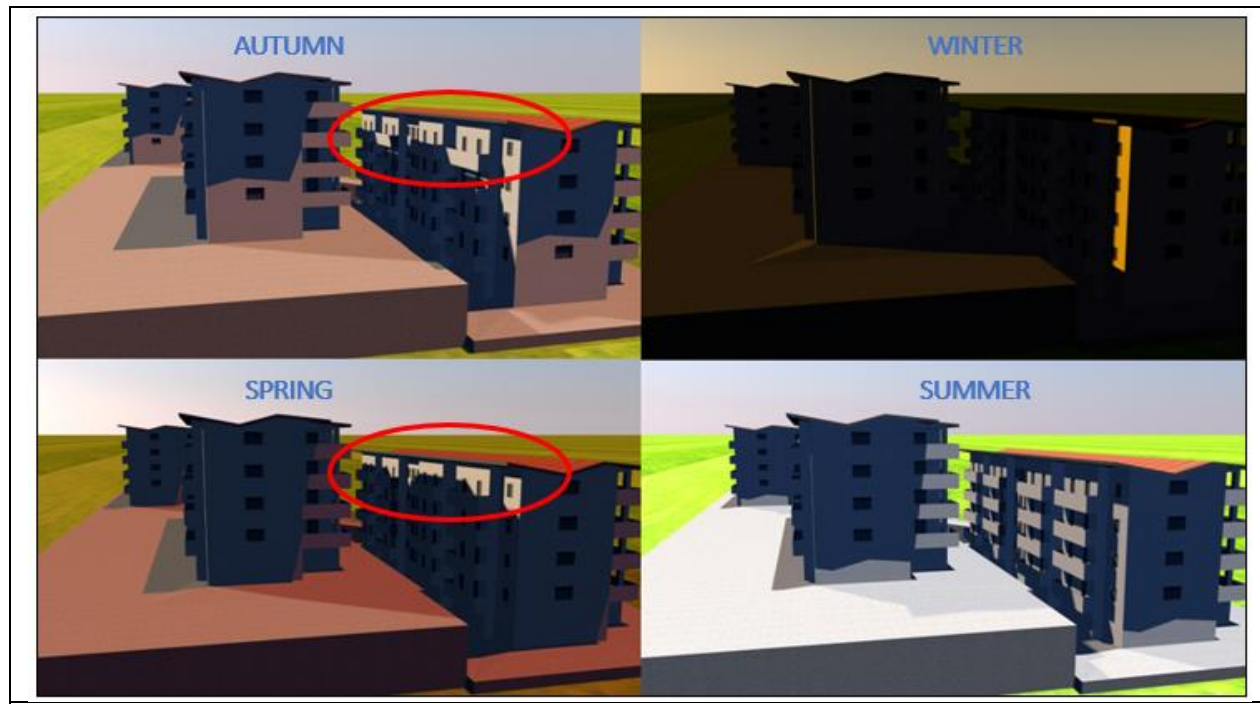

Fig. 5 Qh, sol analysis at 9 a.m. on the NW esposure, and at 5 p.m on the SW exposure

Figure 4 clearly highlights that columns B1.E1 and B2.E2 are those penalized by their exposition, being lateral. The solar path on the buildings has been simulated with a commercial software (Cinema 4D) along the seasons: renders are shown in Figure 5, where analysis refer to 9 a.m. on the NW esposure, and to 5 p.m on the SW exposure. For the simulations, it can be seen that in the morning, each flat gathers quite the same amount of light (and heat) from sum on the NW exposure; on the contrary, by seeing the SW side, in autumn and spring, the fourth floor is lighted by sun at dawn, as well as column B1.E1 in winter. This hints that results must be read in terms of solar gains and heat transmission, especially for the heating season. Therefore, results of Fig. 6 are prposed, where once againg flats are grouped or ranked.

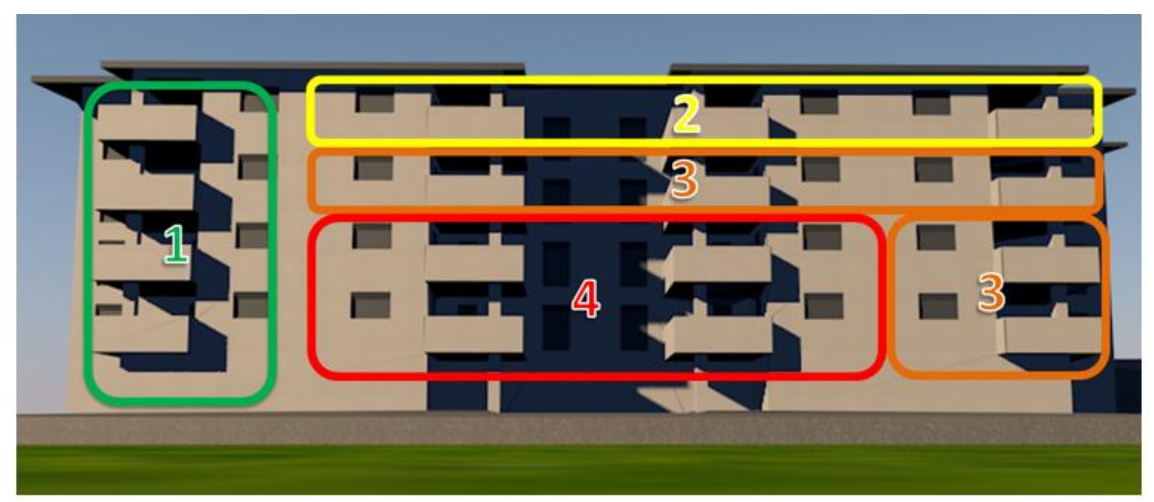




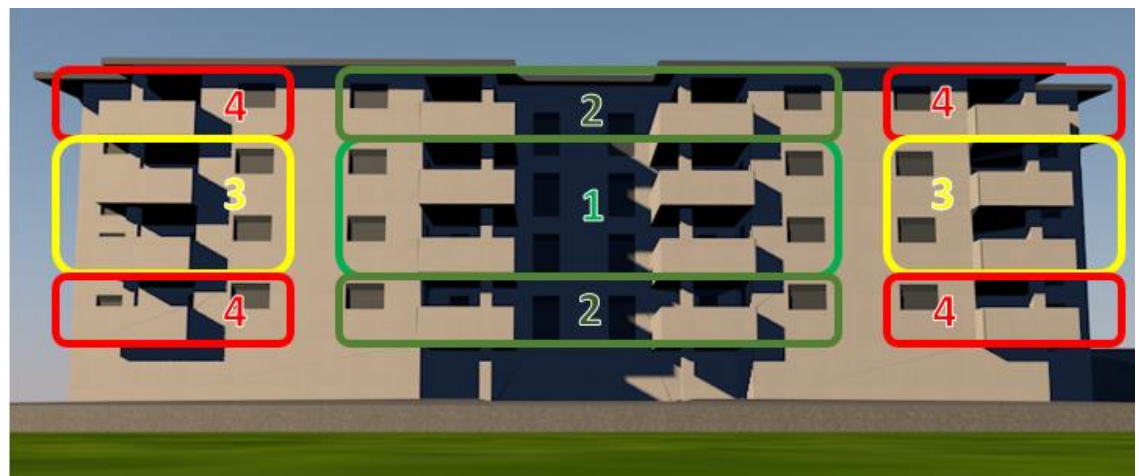

(b)

Fig. 6 Results in terms of: (a) Qh,sol and (b) Qh,tr

For the analysis of Qh,sol, the best column (rank 1) is B1.E1 (since it does not have any building or obstacle in the nearby that projects shadows, as seen also in Fig. 2c). For the remaining flats, the ones with lower solar gains are those in the first floor, followed by the ones on the second and on the third. This agrees with the projection of Fig. 2b). Then, heat losses for transmission have been evaluated, to assess (and confirm) the influence of the boundary conditions determined on the central flats. Results are ranked in Fig.6 b).

Finally, solar gains and transmission losses have been compared for each column of the two buildings, both in the ex-ante and ex-post configurations. Results are shown in Fig.7. where it is evident that before reconstruction transmission losses were high for all the apartments, and orders of magnitudes higher than the solar gains. 


\section{EX-ANTE}

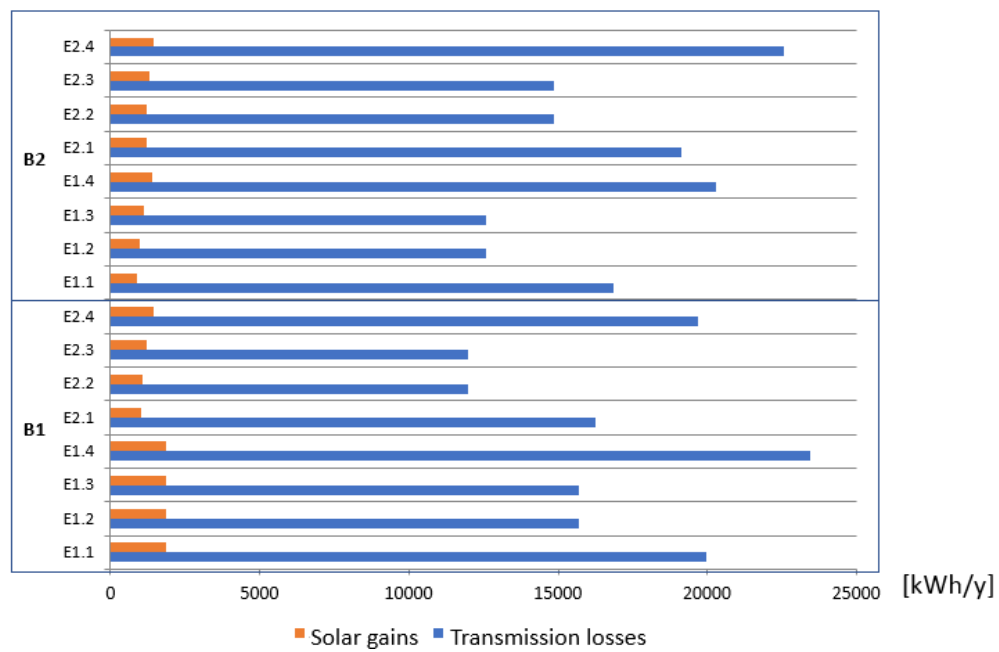

EX-POST

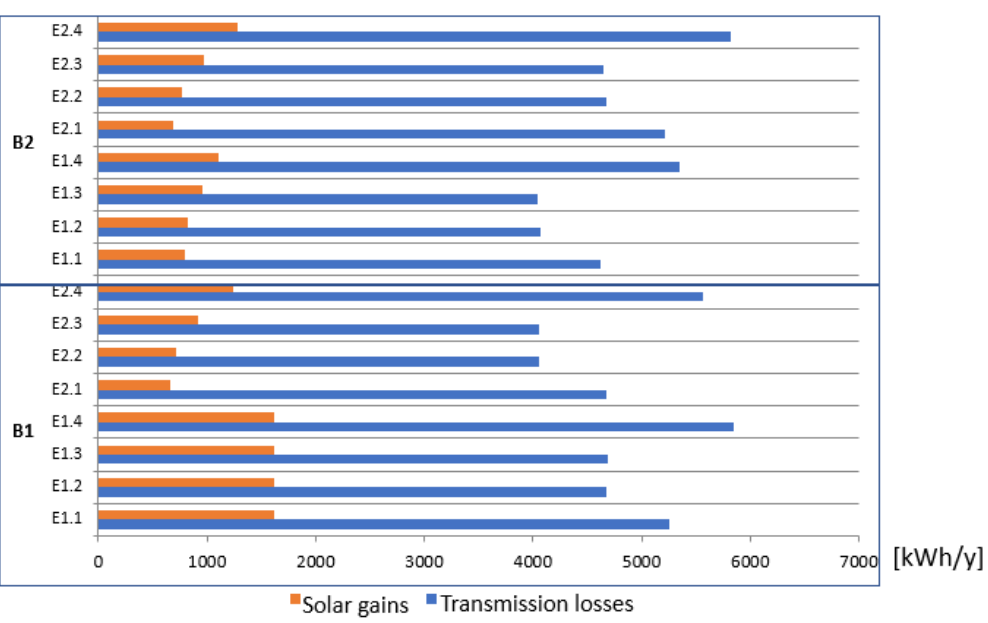

a)

b)

Fig. 7 Tranmission losses and solar gains before (a) and after (b) recontruction

This effect was preponderant in the final evaluation (energy label) of the flats, that, in fact, were all classified as " $G$ ". On the contrary, after reconstruction, the transmission losses are higher (three to four times) than the solar gains, that now play an important role in the final ranking of each flat. This implies a different pattern for the energy labelling, which can influence the building (rental or selling) market. Please also note that from Fig. $2 \mathrm{~b}$ that lower $\mathrm{EP}_{\mathrm{gl}, \text { nren }}$ does not automatically corresponds to higher grades, as happens for flats B1.E1.1 and B1.E1.2 (this depends on the way the grads are evaluated according to the Italian law). This can contribute to mislead the final user in his choice. In fact, which apartment is more suitable to be recommended to a potential buyer? Answer this question is not so easy, as seen by these results. 


\section{Conclusions}

When choosing a housing solution, many aspects must be addressed. Pretending to be a final user, it is normal to expect that, at equal prices, you get more attracted by the better energy label. However, as proven in this work, the energy label by itself can mislead the proper evaluation of a building or flat. This datum is meaningless when not paired with the total energy consumption of the building itself, and with other side considerations on issues like solar gains or transmission losses. In this paper, such evaluations have been pointed out on a real building, showing that flats layout and shadings might affect, in relevant ways, total energy consumptions, and/or the energy label associated to each flat.

In fact, by coupling commercial softwares, it is possible to compare the main energy consumption index of flats, and to assess which are the ones penalized by their exposure. Indeed, by comparing the solar gains and the transmission losses, it is possible to rank the flats. Such consideration can be done before and after reconstruction, in order to infer if and how such ranking can change due to the effect of solar gain and transmission losses.

As a whole, exposure and shading due to other buildings are very relevant for flats energy performance: their contribution to total energy performance are higher when transmission losses get lower. Flats not shaded by side buildings can benefit of higher solar gain but, on the other hand, might have higher transmission losses due to their positioning in the building (they are generally on the highest floor). On the contrary, flats in the middle, which have lower transmission losses, also have lower solar gains.

Before reconstruction, transmission losses were high for all the apartments, and orders of magnitudes higher than the solar gains; after reconstruction, the transmission losses are three to four times the solar gains, but their relative weight for the energy label has changed. In fact, after reconstruction, solar gains play an important role in the final ranking of each flat. This implies a different pattern for the energy labelling (before reconstruction, all flats were classifiedg “G”).

\section{References}

1. Directive $2002 / 91 / C E$ (EPBD - Energy Performance of Building Directive)

2. Directive 2012/27/EU of the European Parliament and of the Council of 25 October 2012 on energy efficiency, amending Directives 2009/125/EC and 2010/30/EU and repealing Directives 2004/8/EC and 2006/32/EC (2012)

3. C. Zeng, S. Liu, A. Shukla, B. Yang, J. Build. Eng. 18, 281-291 (2018)

4. W. O'Brien et al., Build. Environ. (to be published 2020) https://doi.org/10.1016/j.buildenv.2020.106906

5. M. Ashouri, B. C.M. Fung, F. Haghighat, H. Yoshino, Energy, 194, 116813 (2020)

6. Y. Zhang, C. Xiao, G. Zhou, J Clean Prod 242, 118555 (2020)

7. L.G. Giraudet, Energy Econ., 87, 104698 (2020)

8. M. Olsthoorn, J. Schleich, S. Hirzel, Ecol. Econ., 136, 240-254 (2017)

9. L. Zhang, Y. Li, R. Stephenson, B. Ashuri, Energ Build 158, 1226-1240 (2018)

10. L. Tronchin, K. Fabbri, Energ Policy 48, 176-184 (2012)

11. F. Fantozzi, F. Leccese, G. Salvadori, G. Tuoni, WIT Transactions on Ecology and the Environment, Vol 122, (2009) 